Fluorocarbon compatibilized gold-silica nanocomposites for recyclable regioselective hydroamination of alkynes in a fluorous biphasic system

Zulkifli Merican, Bao Khanh Vu, Vera A. Solovyeva, Valentin O. Rodionov, Cheng Seong Khe, Sokkalingam Rajalingam, and Pandian Vasant

Citation: 1787, 030014 (2016); doi: 10.1063/1.4968079

View online: http://dx.doi.org/10.1063/1.4968079

View Table of Contents: http://aip.scitation.org/toc/apc/1787/1

Published by the American Institute of Physics 


\title{
Fluorocarbon Compatibilized Gold-Silica Nanocomposites For Recyclable Regioselective Hydroamination of Alkynes In A Fluorous Biphasic System
}

\author{
Zulkifli Merican ${ }^{1, \text { a }}$ Bao Khanh $\mathrm{Vu}^{2}$, Vera A. Solovyeva ${ }^{3}$, Valentin O. Rodionov ${ }^{4}$, \\ Cheng Seong Khe ${ }^{5}$, Sokkalingam Rajalingam ${ }^{6}$, Pandian Vasant ${ }^{7}$ \\ ${ }^{1,5,6,7}$ Department of Fundamental and Applied Sciences, Universiti Teknologi PETRONAS, 32610, Bandar Seri \\ Iskandar, Perak, Malaysia \\ ${ }^{2,3,4}$ Centre for Catalysis, Division of Chemicals, Life Sciences \& Engineering, \\ King Abdullah University of Science \& Technology, \\ Thuwal 23955-6900 Kingdom of Saudi Arabia \\ a)Corresponding author: zulkifli.aljunid@petronas.com.my \\ ${ }^{2)}$ vu.khanh@ntt.edu.vn \\ 3) vera.solovyeva@kaust.edu.sa \\ 4) valentin.rodionov@kaust.edu.sa \\ 5) chengseong.khe@petronas.com.my \\ 6) raja.sokkalingam@petronas.com.my \\ ${ }^{7)}$ pandian_m@petronas.com.my
}

\begin{abstract}
The synthesis and characterization of the mesoporous silica-supported gold (Au@mSiO2) nanoparticles compatibilized with the outer shelled superhydrophobic fluorous (F) "tails" was described. The concept of fluorous biphasic separation was applied in the recycling of the synthesized fluorous material during hydroamination reactions of various alkynes. In the presence of perfluoromethylcyclohexane and heptane as a biphasic liquid system, the F-Au@mSiO2 was found to be a highly active catalyst for hydroamination of various alkynes with anilines, and a near quantitative yield for an imine product and produced a relatively minimal formation of a corresponding hydrolyzed ketone by-product. If perfluoromethylcyclohexane and heptane was used as a biphasic solvent, hydroamination at a lower reaction temperature can also be realized leading to an improved recyclability and conversion.
\end{abstract}

\section{INTRODUCTION}

Gold nanoparticles (AuNPs) exhibit an extensive range of useful properties that differ significantly from those of bulk gold. For example, depending on their precise size, they can exhibit a strong absorption band in the visible region, as first described theoretically by Mie [1], surface-enhanced Raman scattering (SERS) of absorbed molecules [2], catalytic behavior [3, 4], quenching of proximal fluorophores $(<5 \mathrm{~nm}$ from surface) [5, 6], and enhanced fluorescence of chromophores at a distance of $>10 \mathrm{~nm}$ [5]. The size, shape and degree of aggregation of AuNPs have a significant effect on the nature of these properties. Unless a method for controlling the particles aggregation is available at hand $[7,8]$, AuNPs if left unstabilized, can readily aggregate to such an extent that these properties are lost. For applications of AuNPs in catalysis, it is widely known under normal circumstances, gold is far too noble to act as an effective catalyst, but that changes when it is present as very small finely divided nanoparticles. The observation that gold, in this form, can be exceptionally active as a catalyst has spurred a great number of initial discoveries $[9,10]$. Gold, either in nanocrystalline form as colloids or supported in some way, or as discrete cationic complexes, are finding particular favor as versatile and selective catalysts for high-value synthetic transformations. 
One such transformation is hydroamination, which provides a synthesis route to the direct formation of a new C-N bond by addition of an amine to an unsaturated C-C bond, offers not only an atom-efficient pathway starting from readily accessible alkenes and alkynes, but it also provides nitrogen-containing compounds, such as amines, enamines, and imines, all of these are valuable and commercially important bulk chemicals, specialty chemicals and pharmaceuticals [11]. Despite the addition of amines to non-activated C-C multiple bonds (hydroamination) is a highly desired reaction, it is still a difficult chemical transformation. A particular challenge to this transformation can be attributed to the reversal of the regiochemistry to obtain adequate control of the regioselectivity in anti-Markovnikov fashion [12]. As a consequence, a highly efficient catalyst is required for the above reason, but also to tackle a few other challenges in hydroamination, viz. (i) the reaction enthalphy, which is slightly negative for most (intermolecular) hydroamination reactions [13], prohibits accelerating the reaction by using high temperatures because the thermodynamic equilibrium is encountered [14]; and (ii) repulsion between the nitrogen lone pair and the olefin/alkyne $\pi$-system [15].

For asymmetric hydroamination reactions, their main catalytic pathways can be attributed to a variety of metals [16], bases [17] and Bronsted acids [18]. Late transition metals (Ir, Pd, Au, Rh) are highly attractive and desirable for asymmetric hyroaminations due to higher functional group tolerance for both inert- and intramolecular variants, lowest air and moisture sensitivity and provide higher enantioselectivities [19]. However, to date there are only a few reports of gold-catalyzed enantioselective hydroamination reactions, for instance the catalysts reported were dinuclear gold(I)-phosphine complexes with biaryl-based backbone [20]. We sought to use an alternative method whereby in line with previous work on silica supported metal nanoparticles in our lab [21], to design and synthesize perfluorocarbon compatibilized gold-silica supported nanoparticles. It is hypothesized that the particles due to the presence of the fluorous shell are able to catalyze hydroamination reactions of alkynes via a fluorous biphasic catalysis (FBC) technique. Such a combination of using gold catalysis in hydroamination reactions while exploiting the FBC technique, would allow for catalyst recyclability, useful for cascade transformations and recovery, to name a few.

Scheme 1. Synthesis of CTAB-protected Au particles $\mathbf{2}$ and compatibilization of mesoporous $\mathrm{SiO}_{2}$ supported Au particles $\mathbf{3}$ with perfluorous "tails" 1 . The resulting F-compatibilized 4 were applied in catalyzed hydroamination reactions utilizing a fluorous biphasic system for ease of separation and recyclability.

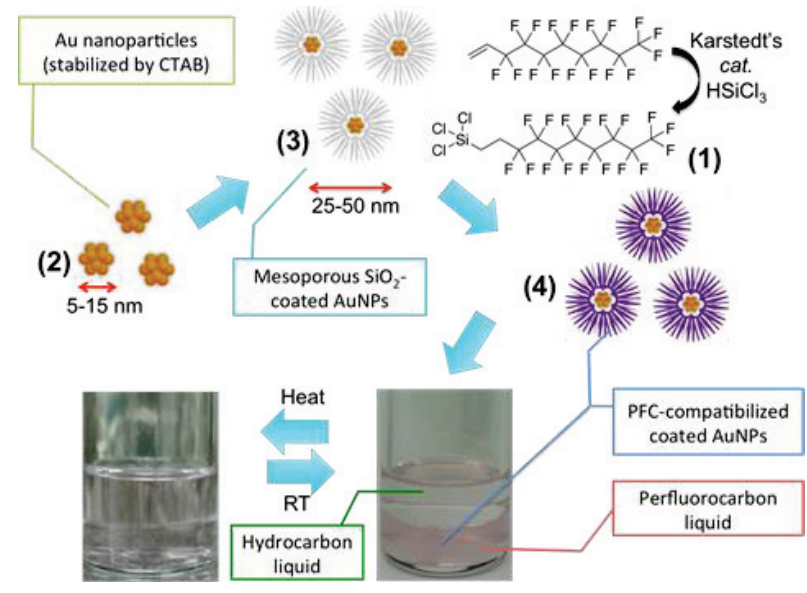

Together with the unique properties of perfluorocarbon fluids to be used in a fluorous biphasic system [22, 23], the reaction employed a heterogeneous catalyst that has been modified in order to make it preferentially soluble in a fluorous phase, separate from the substrate and product phase. These unique properties of pefluorocarbon fluids ranges from being extremely hydrophobic and lacking hydrogen bonding capabilities, which renders them relatively insoluble in their hydrocarbon analogues, to their ability to dissolve various gases such as oxygen and carbon dioxide [24]. FBC has been demonstrated for many catalytic reactions. Some examples are hydroboration [25], hydrosilylation [26], Stille coupling [27], and this list is likely to continue to grow as interest increases in this area. To the best of our knowledge, hydroamination of alkynes over fluorous gold-silica supported catalysts that exploit the benefits of fluorous biphasic system has yet not been reported in literature. 


\section{EXPERIMENTAL}

Synthesis of trichloro $(3,3,4,4,5,5,6,6,7,7,8,8,9,9,10,10,10$-heptadecafluorodecyl)silane (compound 1). The compound was synthesized following a modified procedure from literature [28]. To a mixture of 3,3,4,4,5,5,6,6,7,7,8,8,9,9,10,10,10-heptadecafluorodec-1-ene (15 g, $0.034 \mathrm{~mol})$ and Karstedt's catalyst $(4.5 \mathrm{~mL})$, $\mathrm{HSiCl}_{3}(13.8 \mathrm{~mL})$ was added drop wisely under a nitrogen atmosphere. After the addition, the reaction mixture was stirred at $60{ }^{\circ} \mathrm{C}$ for $25 \mathrm{~h} .{ }^{1} \mathrm{HNMR}$ analysis at this stage suggested a full conversion of the product and a complete disappearance of the starting alkene. Subsequently, the solution was distilled to give $\mathbf{1}$ as a colorless liquid (78 \% yield, b.p. $70-80 \mathrm{C} / 0.04$ torr). ${ }^{1} \mathrm{H}$ NMR $\left(400 \mathrm{MHz}, \mathrm{CDCl}_{3}\right) \delta 2.42-2.21\left(2 \mathrm{H}, \mathrm{m}, \mathrm{CF}_{2} \mathrm{CH}_{2}\right), 1.72-1.60(2 \mathrm{H}, \mathrm{m}$, $\left.\mathrm{CH}_{2} \mathrm{SiCl}_{3}\right) .{ }^{13} \mathrm{C} \mathrm{NMR}\left(101 \mathrm{MHz}, \mathrm{CDCl}_{3}\right) \delta 24.7(\mathrm{t}, J=23.7 \mathrm{~Hz}), 14.8 .{ }^{19} \mathrm{~F} \mathrm{NMR}\left(377 \mathrm{MHz}, \mathrm{CDCl}_{3}\right) \delta-80.91,-115.69$, $-121.80,-122.02,-122.83,-123.24,-126.25$.

Preparation of CTAB-protected Au nanoparticles CTAB-AuNPs (Au nanoparticles 2). The nanoparticles were synthesized following an established method [29]. CTAB (5.0 g) was added to a mixture of deionized water (500 $\mathrm{mL})$ and ethanol $(50 \mathrm{~mL})$. The resultant mixture was sonicated until obtaining a transparent solution, and then an aqueous solution of $\mathrm{HAuCl}_{4} 30 \mathrm{wt} . \%(0.15 \mathrm{~mL})$ was dropped wisely while stirring at $800 \mathrm{rpm}$. We have slightly modified the above procedure by using a higher $\mathrm{CTAB}$ concentration added in batches in order to obtain a smaller gold particle size. Because of the higher concentration of the CTAB containing gold aqueous solution, a gentle heating at $55^{\circ} \mathrm{C}$ helped to re-disperse the gold colloids. Following this, an aqueous solution of $\mathrm{NaBH}_{4}\left(50 \mathrm{mg}\right.$ in $10 \mathrm{ml} \mathrm{H}_{2} \mathrm{O}$ at $4{ }^{\circ} \mathrm{C}$ ) was added gradually, and the $\mathrm{CTAB}$-protected $\mathrm{Au}$ was obtained after stirring for $1 \mathrm{~h}$ at the same heating temperature. The color of the as-synthesized gold solution was a typical wine-red.

Synthesis of mesoporous $\mathrm{SiO}_{2}$ supported AuNPs $\left(\mathrm{Au} @ \mathrm{mSiO}_{2}\right.$ 3). Prior to coating of a silica layer, the obtained Au colloidal solution 2 was adjusted to $\mathrm{pH} 9.7$ by an aqueous solution of $\mathrm{NaOH}(0.2 \mathrm{M})$. To this mixture was then treated with eight additions of $3.3 \mathrm{~mL}$ tetraethoxysilane (TEOS) [30] (17 v/v in methanol) with an interval of 30 min. The growth of silica shells on Au nanoparticles was lasted for 3 days at room temperature. To obtain porosity on the silica, some CTAB was removed by washing the resulting core-shell $\mathrm{Au} @ \mathrm{mSiO}_{2}$ particles 3 with an ethanoic solution of $\mathrm{NH}_{4} \mathrm{NO}_{3}(0.6 \mathrm{~g}$ in $150 \mathrm{~mL}$ ethanol) [31]. The clean core-shell particles were collected by centrifuging at $15,000 \mathrm{rpm}$ for $2 \mathrm{~h}$, and freeze-dried for a few days to afford a red fluffy solid.

F-compatibilized mesoporous $\mathrm{SiO}_{2}$ coated AuNPs (F-Au@mSiO 2 4). Dry mesoporous $\mathrm{SiO}_{2}$ coated $\mathrm{Au}$ particles $2\left(37 \mathrm{mg}\right.$, pre-dried in vacuum at $80{ }^{\circ} \mathrm{C}$ in the presence of phosphorous pentoxide in order remove traces of water) was dispersed in $8.5 \mathrm{~mL}$ of anhydrous trifluorotoluene. Then, $800 \mu \mathrm{L}$ of the fluorous "tails" 1 and $250 \mu \mathrm{L}$ of freshly distilled triethylamine were added to the suspension. The mixture was stirred by a glass magnetic stirrer at 500 $\mathrm{rpm}$ for $10 \mathrm{~h}$. In order to avoid the hydrolysis of unreacted 1, the crude reaction mixture was quenched with 1-octanol, which can be taken up in dichloromethane. The particles were centrifuged and washed several times with dichloromethane. Finally, the particles were dried under a reduced pressure at $80^{\circ} \mathrm{C}$.

General procedure for a hydroamination catalyzed reaction. To a 4-mL screw-cap vial was added the particles 4 (5 mg, 1.14x $10^{-4} \mathrm{mmol}$ per wt \% Au loading) followed by a fluorous-based solvent (perfluoromethylcyclohexane). To the resulting pink suspension was added an organic solvent (heptane) which forms a biphasic system at ambient temperature. To the mixture was added relevant acetylene and aniline substrates ( $1 \mathrm{mmol}$ for each substrate). The vial was sealed and the reaction mixture was stirred vigorously $(1000 \mathrm{rpm})$ at the indicated temperature.

General sample preparation for GCMS analysis. At the completion of a catalytic reaction, a reaction aliquot $(100 \mu \mathrm{L})$ was taken from the organic phase and was added to a chlorobenzene/toluene internal standard $(500 \mu \mathrm{L})$. The aliquot containing the internal standard was subsequently diluted $1 / 8^{\text {th }}$ with toluene and the resulting mixture was filtered off and analyzed by GCMS.

\section{RESULTS AND DISCUSSION}

The synthesis of the fluorous environment for $\mathrm{F}-\mathrm{Au} @ \mathrm{mSiO}_{2}$ ) nanoparticles was provided by the surface active long perfluorocarbon "tails" 1 which was synthesized by hydrosilylation [28] of 1H,1H,2H-heptadecafluorodec-1-ene alkene with trichlorosilane (Scheme 1). Cetyltrimethylammonium bromide (CTAB)-protected Au nanoparticles were synthesized by an established method [29] in which a slight modification to the procedure were required. In this instance, we used a higher $\mathrm{CTAB}$ concentration in order to obtain a smaller gold particle size. Because of the higher concentration of $\mathrm{CTAB}$ containing gold aqueous solution, a gentle heating was required to re-disperse the gold colloids prior to the addition of the reducing sodium borohydride solution. The preparation of $\mathbf{3}$ was achieved by growing a silica shell on the Au surface through the condensation of TEOS in a basic aqueous mixture [30]. After a desirable thickness of the shell was achieved, the resulting core-shell $\mathrm{Au} @ \mathrm{mSiO}_{2}$ particles were washed with an ethanoic solution of sodium nitrate [31], to remove some of the CTAB, hence creating porosity on the silica. 
Following the synthesis of $\mathbf{3}$, they were subsequently compatibilized with $\mathbf{1}$. In order to minimize the hydrolysis of the silane during the synthesis, we used freshly dried fluorocarbon soluble solvent (trifluorotoluene) during the compatibilizing reaction. In the work-up stage, the mixture of excess $\mathbf{1}$ and the resulted F-compatibilized particles 4 were quenched with a long-chain alcohol (1-octanol), washed and collected repeatedly by centrifuging with dichloromethane and trifluorotoluene. The success of the perfluorocarbon coating on $\mathbf{4}$ renders its solubility in perfluorocarbon fluids such as perfluoromethylcyclohexane, perfluorodecalin, perfluorooctane and to some extent in $\alpha, \alpha, \alpha$-trifluorotoluene.

The morphology of the uncoated particles $\mathbf{3}$ and F-compatibilized particles 4 were analyzed under SEM. In Figure 1-A, the SEM micrograph of $\mathbf{3}$ show the much more coarse nature of the as-synthesized silica particles as compared to that of $\mathbf{4}$ which shows a rather smooth coating was apparent, and that particles form more sticky contacts with the neighboring particles (Figure 1-C). On some areas of the SEM grid, we observed agglomerations of 4 (insert in Figure 1-C) indicative of an increase in hydrophobicity upon F-coating, and the resulting particles have a tendency to agglomerate when dried under a usual SEM sample preparation. The as-synthesized mesoporous $\mathrm{Au} @ \mathrm{mSiO} 2$ particles 3 and F-compatibilized particles 4 were also analyzed by TEM. Figure 1-B shows that the overall core-shell diameter of 3 is $28 \pm 1 \mathrm{~nm}$. In comparison, particles $\mathbf{4}$ have a gold particle diameter of $6 \mathrm{~nm}$ (Figure 1-D), and the overall core-shell diameter of $31 \pm 1 \mathrm{~nm}$. In addition, mapping of elements of interest indicates the presence of Si on 3 (Figure 2-B) and the presence of both $\mathrm{Si}$ and $\mathrm{F}$ on F-compatibilized particles 4 (Figure 2-H, and Figure 2-I respectively).

We also performed STEM EELS experiments ranging from a single particle to a larger cluster of the uncoated and F-coated particles. For the uncoated F particles 3 regardless of the number of nanoparticles analyzed, the F signal is not detectable. There was no F-K edge signal which is typically observed at $685 \mathrm{eV}$ (Figure 2-C to F). In comparison, when measurements were taken for the F-compatibilized particles 4, we detected the F-K edge signal at the energy loss of $685 \mathrm{eV}$. The observed energy loss further confirmed the elemental analysis above, and is an indicative of the isolation of particles 4 intact, after cycles of purification by centrifugation and rinsing in order to remove the unreacted perfluorous "tails" 1. It is worthy to note that there is a sensitivity limitation of the EELS technique, i.e., when we imaged a single F-coated particle, the F signal was not detectable. However, when we imaged a few particles or a cluster of particles, then the $\mathrm{F}$ signal picked up at $685 \mathrm{eV}$ (Figure 2-L to M).

The F-compatibilized particles 4 were also analyzed by ICP-OES in order to quantitatively measure the gold content of the catalyst. The intensity of this emission is indicative of the concentration of the element within the catalyst, which is found to have 0.45 wt. \% elemental gold. Unless otherwise specified, the mass of 4 used in hydroamination reactions was set to $c a .10 \mathrm{mg} /$ catalyst sample $\left(2.35 \times 10^{-4} \mathrm{mmol}\right.$ per wt \% Au loading).

The F-compatibilized particles $\mathbf{4}$ were used as a studied catalyst to investigate its catalytic activity for hydroamination reactions of alkynes and anilines under fluorous biphasic solvent conditions. In our screening experiments, we tested the ability of various mixtures of perfluorocarbon and hydrocarbon liquids to form a homogeneous mixture upon heating. A 1:1 volume equivalent of perfluorodecalin and toluene forms a homogeneous mixture only when heated up to $130^{\circ} \mathrm{C}$ (Figure 3-A2).

Subsequently, we tested a scope of substrates for hydroamination catalytic runs at $130^{\circ} \mathrm{C}$. The conversion of most alkynes and anilines after $24 \mathrm{~h}$ and the relative selectivity of each corresponding imine product is $>80-96 \%$ and $>90-100 \%$ respectively (Table 1). Within the scope of the reactions, we also observed a zero conversion, for a substrate such as dec-1-yne with aniline. As minimum requirements, catalytic efficiencies measurable by turnover numbers (TONs: mole of product per mole of metal catalyst) of more than 1000 and by turnover frequencies (TOFs: the turnover per unit time) of more than $200 \mathrm{~h}^{-1}$ are generally considered [32]. Our catalytic material 4 satisfies the minimum TON requirement with measured TONs between $2300-4100$. The blank runs at $130{ }^{\circ} \mathrm{C}$ using substrates that previously gave a high conversion with $\mathbf{4}$, however does not show any conversion $(\mathrm{TON}=0)$. 


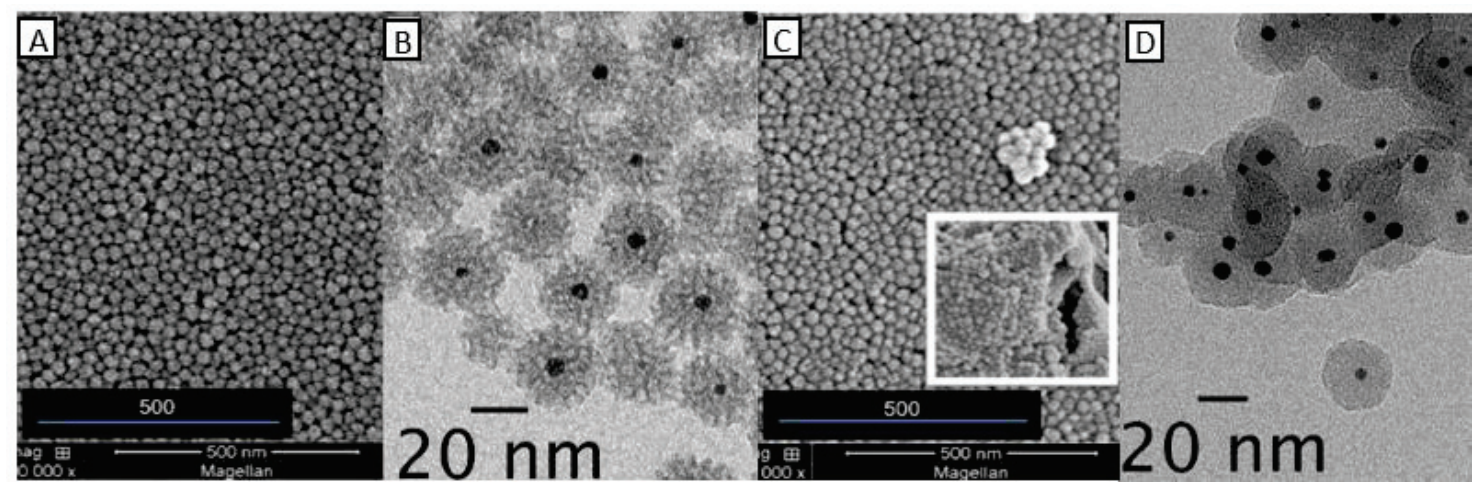

Figure 1. SEM (A) and TEM micrographs (B) of nanoparticles 3 prior to F-coating; and SEM (C) and corresponding TEM micrographs (D) of F-compatibilized 4 and particle agglomerations (insert, Figure 1-C).

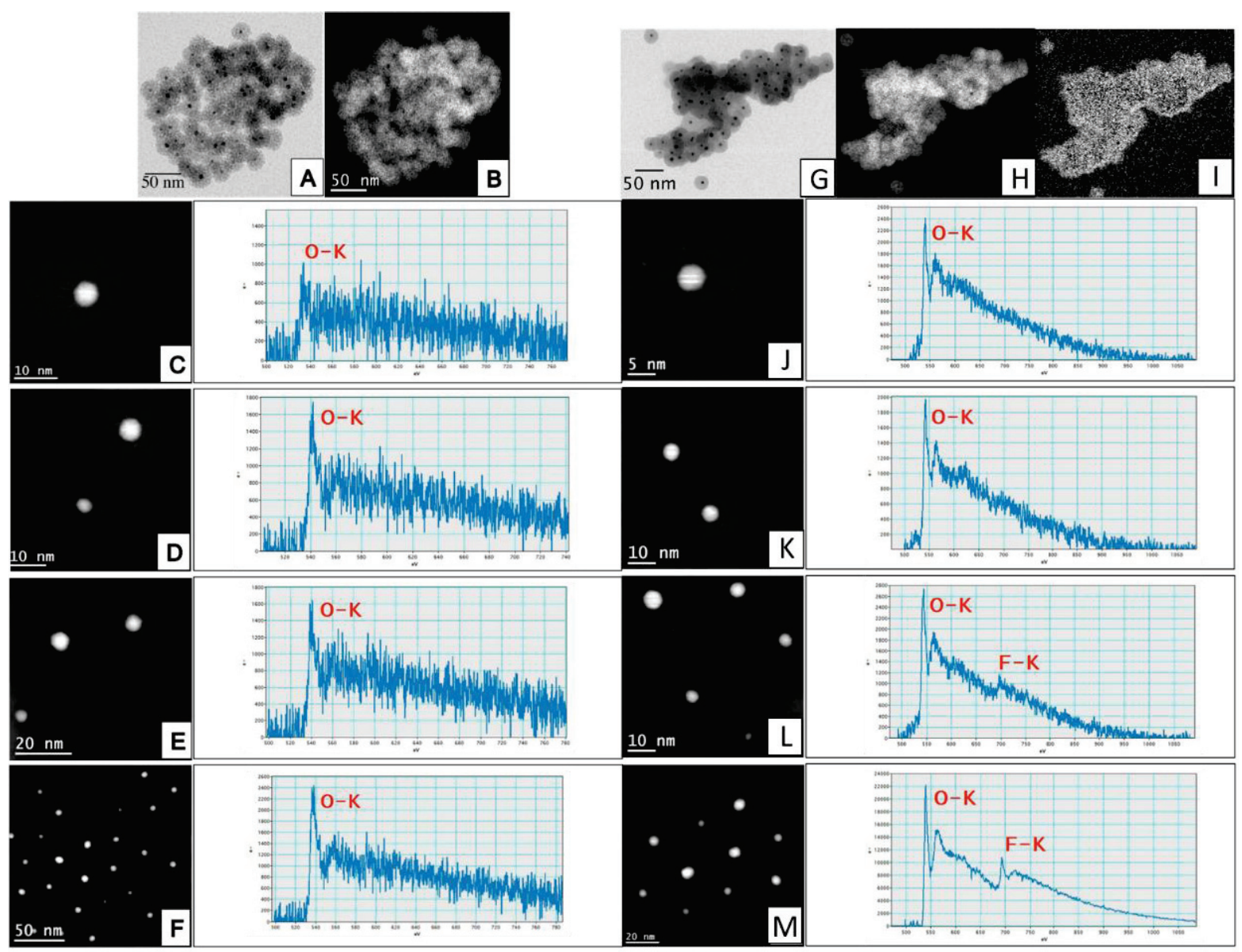

Figure 2. TEM micrographs of the non-F-compatibilized 3: from the bright field image (A), its elemental mapping analysis for Si (B); and STEM EELS analyses performed on corresponding F mapping of a single particle (C); twin particles (D); three adjacent particles (E); and a cluster of particles (F). TEM micrographs of the F-compatibilized 4: from the bright field image $(\mathrm{G})$; its elemental analysis for Si mapping (H); F mapping (I); and STEM EELS analyses performed on corresponding $\mathrm{F}$ mapping of a single particle $(\mathrm{J})$; twin particles $(\mathrm{K})$; five particles $(\mathrm{L})$; and a cluster of particles $(\mathrm{M})$. 
From the results obtained from the scope experiments, we further demonstrated the recyclability of the catalytic particles 4 on the substrates that previously gave high conversions at $24 \mathrm{~h}$ under the same reaction conditions in Table 1, i.e., phenylacetylene (conv. $86 \%$, entry 1b), 4-pentylphenylacetylene (conv. $96 \%$, entry 6b) and 1-ethyl4-ethynylbenzene (conv. $86 \%$, entry $9 \mathrm{~b}$ ). Although the selectivity of the corresponding imine was maintained at full, the TONs for these substrates dropped, being the lowest in the series was from 1-ethyl-4-ethynylbenzene and aniline which recorded a TON of 641 (Entries 1-3, Table 2).

In order to focus attention on a lower reaction temperature, we mixed a range of other liquids. Figure 3 shows the effect of heating to a selection of biphasic liquid systems. At $90{ }^{\circ} \mathrm{C}$, while perfluoromethylcyclohexane-1,2dichloroethane remains non-homogeneous (Figure 3-B4), the perfluoromethylcyclohexane-heptane mixture on the other hand become homogeneous at the same heating temperature (Figure 3-C6). The perfluoromethylcyclohexanehexane biphasic liquids (Figure 3-D7) were ruled out because it already forms a homogeneous mixture at room temperature, which defeats its original purpose for the ease of catalyst recovery.

Accordingly, we described below the findings from the recyclability studies of the catalyst against several selected perfluoro-hydrocarbon biphasic systems. With the perfluorodecalin-toluene biphasic system, the loss of activity after the first catalytic cycle was presumably due to high temperature of the reaction that was responsible for gold leaching [33] (Figure 4-A). Following this, we explored a lower reaction temperature of $90{ }^{\circ} \mathrm{C}$ using a biphasic mixture of perfluoromethylcyclohexane and1,2-dichloroethane. However at this temperature, homogeneity of the two liquids was compromised, resulting in the reduced conversions and loss of catalytic activity (Figure 4-B). In order to use a lower reaction temperature and at the same time maintaining solution homogeneity, we found that the combination of a 1:1 perfluoromethylcyclohexane-heptane solvent gave the optimal biphasic medium which leads to an improved recyclability and the conversion was observed at $76 \%$ with a $98 \%$ selectivity for $(E)-N-(1-(4-$ pentylphenyl)ethylidene)aniline (product $\mathbf{A}$ in Figure 4-C). The catalytic material 4 used in this biphasic system could maintain its activity and selectivity up to 2 cycles.

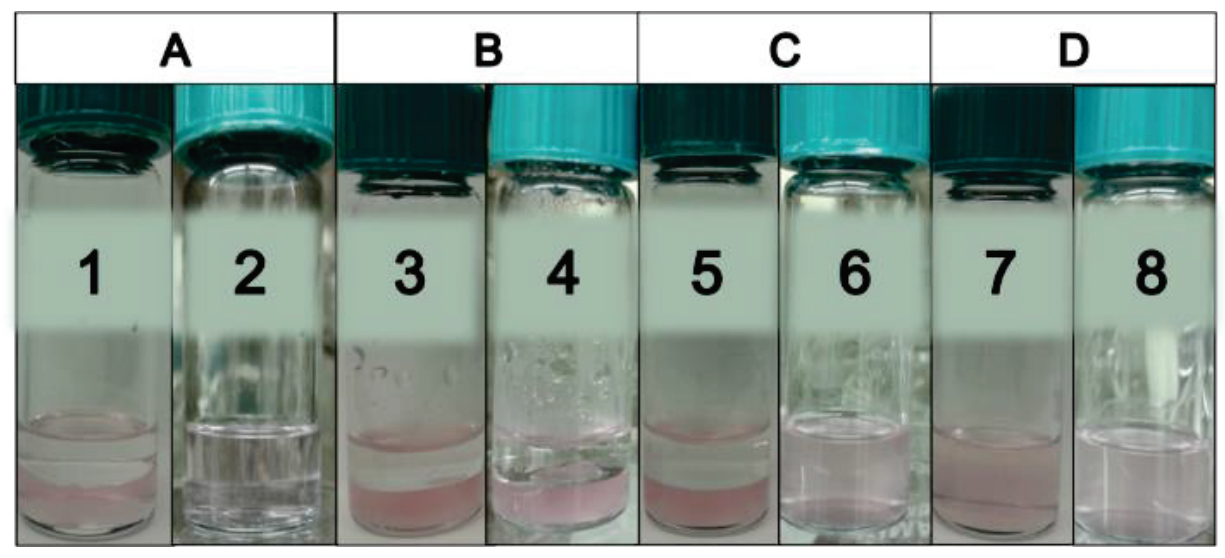

Figure 3. Digital images showing four biphasic mixtures of perfluoro-hydrocarbon liquids and their homogeneity tests with heating. Perfluorodecalin-toluene (A); perfluoromethylcyclohexane-1,2-dichloroethane (B); perfluoromethylcyclohexane-heptane (C); and perfluoromethylcyclohexane-hexane (D). The effect of heating (vial no.): at $\mathrm{T}=130{ }^{\circ} \mathrm{C}$ (no. 2); at $\mathrm{T}=90{ }^{\circ} \mathrm{C}$ (no. 4,6 and 8 ); and their control experiments at $\mathrm{T}=21^{\circ} \mathrm{C}$ (no. 1, 3, 5 and 7). 
Table 1. Hydroamination of alkynes with anilines via a FBC method. ${ }^{\mathrm{a}}$

\begin{tabular}{|c|c|c|c|c|c|c|c|}
\hline \multirow[b]{2}{*}{ Entry } & R2 & $\begin{array}{r}\text { 1. catalyst } \mathrm{p} \\
\text { uorocarbon } \\
0.5 \mathrm{~mL}: 0 \\
\triangle\end{array}$ & $\begin{array}{l}\text { cles } 4 \\
\text { drocarbon } \\
\mathrm{L}\end{array}$ & $R_{1}$ & A & & \\
\hline & $\mathrm{R}_{1}$ & $\mathrm{R}_{2}$ & $\begin{array}{l}\text { Time } \\
\text { (h) }\end{array}$ & Conv (\%) & $\begin{array}{r}\text { Selec } \\
\text { A }\end{array}$ & $\begin{array}{l}y(\%) \\
\text { B }\end{array}$ & $\mathrm{TON}^{\mathrm{c}}$ \\
\hline 1a. & $\mathrm{Ph}$ & $\mathrm{H}$ & 14 & 81 & $>99$ & $<1$ & 3460 \\
\hline $1 \mathrm{~b}$. & $\mathrm{Ph}$ & $\mathrm{H}$ & 24 & 86 & $>99$ & $<1$ & 3673 \\
\hline $2 \mathrm{a}$. & $\mathrm{Ph}-p-\mathrm{OPh}$ & $\mathrm{H}$ & 14 & 91 & 95 & 5 & 3838 \\
\hline $2 \mathrm{~b}$ & $\mathrm{Ph}-p-\mathrm{OPh}$ & $\mathrm{H}$ & 24 & 93 & 93 & 7 & 3922 \\
\hline $3 a$. & $\mathrm{Ph}-p-\mathrm{NH}_{2}$ & $\mathrm{H}$ & 14 & 89 & 93 & 7 & 3686 \\
\hline $3 \mathrm{~b}$. & $\mathrm{Ph}-p-\mathrm{NH}_{2}$ & $\mathrm{H}$ & 24 & 92 & 94 & 6 & 3810 \\
\hline $4 a$. & 1-naphthyl- & $\mathrm{H}$ & 14 & 77 & 100 & 0 & 3279 \\
\hline $4 \mathrm{~b}$ & 1-naphthyl- & $\mathrm{H}$ & 24 & 77 & 100 & 0 & 3279 \\
\hline $5 \mathrm{a}$. & $\mathrm{C}_{8} \mathrm{H}_{17}$ & $\mathrm{H}$ & 14 & 0 & - & - & 0 \\
\hline $5 b$ & $\mathrm{C}_{8} \mathrm{H}_{17}$ & $\mathrm{H}$ & 24 & 0 & - & - & 0 \\
\hline $6 a$. & $\mathrm{Ph}-p-\mathrm{C}_{5} \mathrm{H}_{11}$ & $\mathrm{H}$ & 14 & 96 & $>99$ & $<1$ & 4108 \\
\hline $6 \mathrm{~b}$. & $\mathrm{Ph}-p-\mathrm{C}_{5} \mathrm{H}_{11}$ & $\mathrm{H}$ & 24 & 96 & $>99$ & $<1$ & 4108 \\
\hline $7 \mathrm{a}$ & $\mathrm{Ph}-p-\mathrm{Br}$ & $\mathrm{H}$ & 14 & 93 & $>99$ & $<1$ & 3992 \\
\hline $7 \mathrm{~b}$ & $\mathrm{Ph}-p-\mathrm{Br}$ & $\mathrm{H}$ & 24 & 94 & $>97$ & $<3$ & 4034 \\
\hline $8 \mathrm{a}$. & $\mathrm{Ph}-p-\mathrm{F}$ & $\mathrm{H}$ & 14 & 83 & $>99$ & $<1$ & 3517 \\
\hline $8 \mathrm{~b}$ & $\mathrm{Ph}-p-\mathrm{F}$ & $\mathrm{H}$ & 24 & 85 & $>99$ & $<1$ & 3602 \\
\hline 9a. & $\mathrm{Ph}-p-\mathrm{C}_{2} \mathrm{H}_{5}$ & $\mathrm{H}$ & 14 & 74 & 93 & 7 & 3161 \\
\hline $9 \mathrm{~b}$. & $\mathrm{Ph}-p-\mathrm{C}_{2} \mathrm{H}_{5}$ & $\mathrm{H}$ & 24 & 86 & 91 & 10 & 3673 \\
\hline 10a. & $\mathrm{Ph}-p$-tert-Bu & $\mathrm{H}$ & 14 & 84 & $>99$ & $<1$ & 3591 \\
\hline $10 \mathrm{~b}$ & $\mathrm{Ph}-p$-tert-Bu & $\mathrm{H}$ & 24 & 84 & 98 & 2 & 3591 \\
\hline $11 \mathrm{a}$. & $\begin{array}{l}\text { 1-(6-methoxy) } \\
\text { naphthyl- }\end{array}$ & $\mathrm{H}$ & 14 & 69 & 100 & 0 & 2927 \\
\hline $11 b$ & $\begin{array}{c}\text { 1-(6-methoxy) } \\
\text { naphthyl- }\end{array}$ & $\mathrm{H}$ & 24 & 77 & 100 & 0 & 3266 \\
\hline $12 \mathrm{a}$. & $\mathrm{Ph}$ & $p-\mathrm{Cl}$ & 14 & 55 & $>99$ & $<1$ & 2338 \\
\hline $12 \mathrm{~b}$ & $\mathrm{Ph}$ & $p-\mathrm{Cl}$ & 24 & 59 & $>99$ & $<1$ & 2508 \\
\hline $13 a$. & $\mathrm{Ph}$ & $p-\mathrm{Me}$ & 14 & 83 & 100 & 0 & 3555 \\
\hline $13 b$ & $\mathrm{Ph}$ & $p-\mathrm{Me}$ & 24 & 80 & 100 & 0 & 3427 \\
\hline
\end{tabular}


Table 2. Repeated hydroamination conversion studies of the chosen substrates: phenylacetylene, 4-pentylphenylacetylene and 1ethyl-4-ethynylbenzene that previously gave high conversions at $24 \mathrm{~h}$ under the same reaction conditions in Table 1.

\begin{tabular}{cccccccc}
$\begin{array}{c}\text { Entry (from } \\
\text { Table 1) }\end{array}$ & $\mathrm{R}_{1}$ & $\mathrm{R}_{2}$ & $\begin{array}{c}\text { Time } \\
\text { (h) }\end{array}$ & $\begin{array}{c}\text { Conv. } \\
(\%)^{\mathrm{b}}\end{array}$ & $\begin{array}{c}\text { Selectivity (\%) } \\
\text { A }\end{array}$ & TON $^{\mathrm{B}}$ \\
\hline 1b. & $\mathrm{Ph}$ & $\mathrm{H}$ & 24 & 20 & 100 & 0 & 854 \\
6b. & $\mathrm{Ph}-p-\mathrm{C}_{5} \mathrm{H}_{11}$ & $\mathrm{H}$ & 24 & 71 & 100 & 0 & 3032 \\
9b. & $\mathrm{Ph}-p-\mathrm{C}_{2} \mathrm{H}_{5}$ & $\mathrm{H}$ & 24 & 15 & 100 & 0 & 641 \\
\hline
\end{tabular}

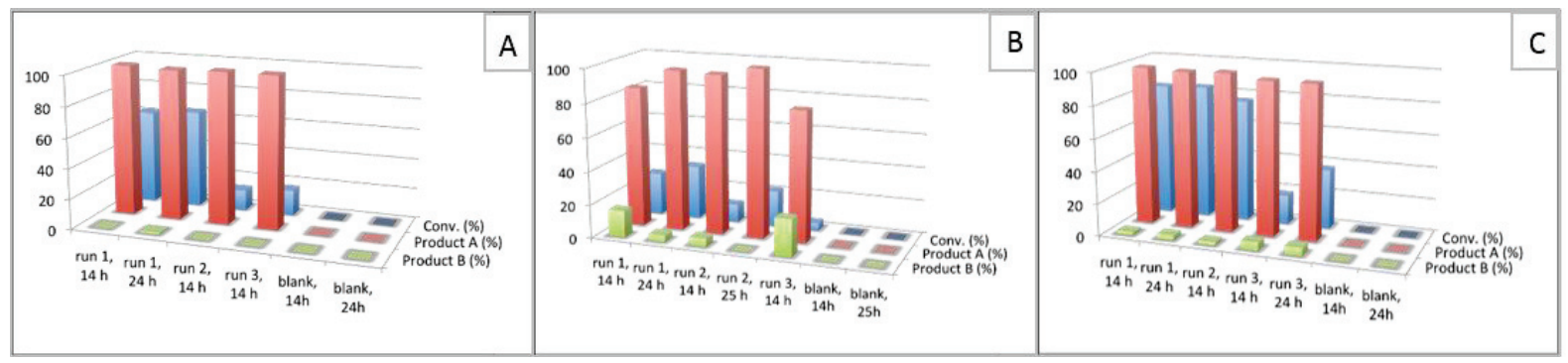

Figure 4. Catalytic particles 4 in the presence of substrates 1-ethynyl-4-pentylbenzene and aniline, were tested for recyclability over three selected perfluoro-hydrocarbons biphasic systems.

\section{CONCLUSION}

The mesoporous silica-supported gold nanoparticles incorporating the superhydrophobic fluorous shell were synthesized, characterized and their catalytic applications were discussed. The F-compatibilized material has a scope for the hydroamination reactions as seen in Table 1. In addition, a fluorous approach to the concept of biphasic catalyst recycling have been successfully applied to the recycling of the catalytic material for the hydroamination of alkynes. Due to its inertness and easy character of the separation technique and optional centrifugation, recycling of the F$\mathrm{Au} @ \mathrm{mSiO}_{2}$ nanoparticles was proven practical, and the material was stable after at least two repetitive hydroamination reactions at a reaction temperature of below $100^{\circ} \mathrm{C}$, and without observable changes in activity and selectivity. In our future work, the concept shall be extended to other metal nanoparticles, such as Pt, Pd, Au-Pt and Rh, as well as smallmolecule organometallic species and organocatalysts with fluorous phase tags. We are interested in applying our perfluorous shelled catalyst methodology to cascade reactions with nanoparticle-incompatible catalysts (such as thioureas) supported on soluble polymeric microcapsules.

\section{ACKNOWLEDGEMENTS}

The authors thanks the KAUST Office of Research Grants for a financial support under a KAUST Baseline Funding program and Dr. Rachid Sougrat from the KAUST Advanced Nanofabrication Imaging and Characterization Core Labs for the STEM-EELS analyses and use of the facilities. Encouragement and support from the Department of Fundamental \& Applied Sciences, Universiti Teknologi PETRONAS is also greatly acknowledged.

\section{REFERENCES}

1. S. Link and M. A. El-Sayed, J. Phys. Chem. B 103 (40), 8410-8426 (1999).

2. S. Nie and S. R. Emory, Science 275 (5303), 1102-1106 (1997).

3. P. Rodriguez, D. Plana, D. J. Fermin and M. T. M. Koper, J. Catal. 311, 182-189 (2014).

4. E. Gross, H.-C. LiuJack, F. D. Toste and G. A. Somorjai, Nat Chem 4 (11), 947-952 (2012).

5. S. Eustis and M. A. El-Sayed, Chem. Soc. Rev. 35 (3), 209-217 (2006). 
6. G. Schneider, G. Decher, N. Nerambourg, R. Praho, M. H. V. Werts and M. Blanchard-Desce, Nano Lett. 6 (3), 530-536 (2006).

7. $\quad$ G. Schneider and G. Decher, Langmuir 24 (5), 1778-1789 (2008).

8. I. Blakey, Z. Merican and K. J. Thurecht, Langmuir 29 (26), 8266-8274 (2013).

9. $\quad$ A. S. K. Hashmi and G. J. Hutchings, Angew. Chem. Int. Ed. 45 (47), 7896-7936 (2006).

10. M. Haruta, Nature 437 (7062), 1098-1099 (2005).

11. J. J. Brunet and D. Neibecker, in Catalytic Heterofunctionalization from Hydroamination to Hydrozirconation, edited by A. Togni and H. Grützmacher (VCH, Weinheim, Germany, 2001), pp. 91-141.

12. S. Borman, Chem. Eng. News 82 (11), 42-43 (2004).

13. J.-J. Brunet, D. Neibecker and F. Niedercorn, J. Mol. Catal. 49 (3), 235-259 (1989).

14. O. Jimenez, T. E. Muller, C. Sievers, A. Spirkl and J. A. Lercher, Chem. Commun. (28), 2974-2976 (2006).

15. T. E. Müller, K. C. Hultzsch, M. Yus, F. Foubelo and M. Tada, Chem. Rev. 108 (9), 3795-3892 (2008).

16. K. Manna, S. Xu and A. D. Sadow, Angew. Chem. Int. Ed. 50 (8), 1865-1868 (2011).

17. P. H. Martinez, K. C. Hultzsch and F. Hampel, Chem. Commun. (21), 2221-2223 (2006).

18. N. D. Shapiro, V. Rauniyar, G. L. Hamilton, J. Wu and F. D. Toste, Nature 470 (7333), 245-249 (2011).

19. N. Nishina and Y. Yamamoto, Angew. Chem. Int. Ed. 45 (20), 3314-3317 (2006).

$20 . \quad$ R. L. LaLonde, B. D. Sherry, E. J. Kang and F. D. Toste, J. Am. Chem. Soc. 129 (9), 2452-2453 (2007).

21. V. A. Solovyeva, K. B. Vu, Z. Merican, R. Sougrat and V. O. Rodionov, ACS Comb. Sci. 16 (10), 513-517 (2014).

22. E. de Wolf, G. van Koten and B.-J. Deelman, Chem. Soc. Rev. 28 (1), 37-41 (1999).

23. E. G. Hope and A. M. Stuart, J. Fluorine Chem. 100 (1-2), 75-83 (1999).

24. L. C. Clark and F. Gollan, Science 152 (3730), 1755-1756 (1966).

25. J. J. J. Juliette, D. Rutherford, I. T. Horváth and J. A. Gladysz, J. Am. Chem. Soc. 121 (12), 2696-2704 (1999).

26. E. de Wolf, E. A. Speets, B.-J. Deelman and G. van Koten, Organometallics 20 (17), 3686-3690 (2001).

27. S. Schneider and W. Bannwarth, Angew. Chem. Int. Ed. 39 (22), 4142-4145 (2000).

28. F.-L. Qing, M. Ji, R. Lu, K. Yan and Z. Mao, J. Fluorine Chem. 113 (1), 139-141 (2002).

29. B. Nikoobakht and M. A. El-Sayed, Chem. Mater. 15 (10), 1957-1962 (2003).

30. L. M. Liz-Marzán, M. Giersig and P. Mulvaney, Langmuir 12 (18), 4329-4335 (1996).

31. N. Lang and A. Tuel, Chem. Mater. 16 (10), 1961-1966 (2004).

32. J. Seayad, A. Tillack, C. G. Hartung and M. Beller, Adv. Synth. Catal. 344 (8), 795-813 (2002).

33. I. Arends and R. Sheldon, Applied Catalysis A: General 212 (1), 175-187 (2001). 